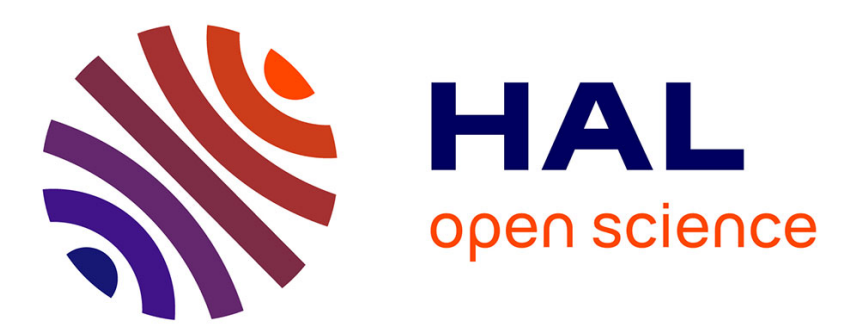

\title{
Stochastic Approach in Wet Snow Detection Using Multitemporal SAR Data
}

Nikola Besic, Gabriel Vasile, Jean-Pierre Dedieu, Jocelyn Chanussot, Srdjan Stankovic

\section{- To cite this version:}

Nikola Besic, Gabriel Vasile, Jean-Pierre Dedieu, Jocelyn Chanussot, Srdjan Stankovic. Stochastic Approach in Wet Snow Detection Using Multitemporal SAR Data. IEEE Geoscience and Remote Sensing Letters, 2015, 12 (2), pp.244-248. 10.1109/LGRS.2014.2334355 . hal-01023156

\section{HAL Id: hal-01023156 https://hal.science/hal-01023156}

Submitted on 11 Jul 2014

HAL is a multi-disciplinary open access archive for the deposit and dissemination of scientific research documents, whether they are published or not. The documents may come from teaching and research institutions in France or abroad, or from public or private research centers.
L'archive ouverte pluridisciplinaire HAL, est destinée au dépôt et à la diffusion de documents scientifiques de niveau recherche, publiés ou non, émanant des établissements d'enseignement et de recherche français ou étrangers, des laboratoires publics ou privés. 


\title{
Stochastic Approach in Wet Snow Detection Using Multitemporal SAR Data
}

\author{
Nikola Besic, Student Member IEEE, Gabriel Vasile, Member IEEE, Jean-Pierre Dedieu, Member IEEE \\ Jocelyn Chanussot, Fellow IEEE, and Srdjan Stankovic, Senior Member IEEE
}

\begin{abstract}
This paper introduces an alternative strategy for wet snow detection using multitemporal SAR data. The proposed change detection method is primarily based on the comparison between two $X$ band SAR images acquired during the accumulation (winter) and the melting (spring) seasons, in the French Alps. The new decision criterion relies on the local intensity statistics of the SAR images by considering the backscattering ratio as a stochastic process: the probability that "the intensity ratio fits into the predetermined range of values" is larger than a defined confidence level. Both the conducted snow backscattering simulations and the state of the art measurements [1] indicate more complex relation between the backscattering properties of the two snow types, with respect to the conventional assumption of the augmented electromagnetic absorption associated to the wet snow. Therefore, rather than adopting the standard hypothesis, we analyse the wet/dry snow backscattering ratio as a function of the local incidence angle (LIA). After employing the multi-layer snow backscattering simulator, calibrated with scatterometer measurements in $\mathrm{C}$ band, we modify, to some extent, the range of ratio values indicating the presence of the wet snow, by including positive ratio values for lower LIA. By simultaneously accounting for the speckle noise, the proposed stochastic approach derives the refined wet snow probability map. The performance analyses are carried out both through the comparison with the ground air temperature map and by comparing two co-polarized channels processed separately.
\end{abstract}

Index Terms-change detection, wet snow, stochastic approach, backscattering simulation

\section{INTRODUCTION}

Depending on the liquid water content, snow can be considered as dry or wet. Dry snow is defined as snow consisted just of ice crystals embedded in air, without any liquid water. Its presence is characteristic for temperatures below $0^{\circ} \mathrm{C}$. Wet snow can be found during the melting season, when the temperature exceeds $0^{\circ} \mathrm{C}$. It contains a certain amount of liquid water introduced quantitatively through the wetness. These two snow types behave differently with respect to their dielectric properties: the wet snow contains liquid water with a dielectric constant differing significantly from the one of the ice. This fact points out to a difference in backscattering mechanisms [2], and consequently that different feature extraction methods should be applied. Therefore, the estimation of any snow pack

Manuscript received October 5, 2013; revised April 17, 2014 and June 11, 2014; accepted June 26, 2014.

N. Besic is with the GIPSA-lab, Grenoble INP, Grenoble, France and with the University of Montenegro, (e-mail: nikola.besic@gipsa-lab.grenobleinp.fr). G. Vasile and J. Chanussot are with the GIPSA-lab, CNRS/Grenoble INP, Grenoble, France. J.-P. Dedieu is with the LTHE, UJF/CNRS, Grenoble, France. S. Stankovic is with the University of Montenegro. parameter by means of SAR remote sensing, requires firstly the proper identification of the snow cover type [3].

Although studies on snow mapping by polarimetric SAR existed already [4], it was not before the ERS-1 started providing repeat pass images that the idea of snow mapping based on SAR multitemporal data appeared [5]. Further refinement on the initial change detection method leaded eventually to the compact algorithm based on the ratio of two $\mathrm{C}$ band SAR images introduced in [6]. The Nagler and Rott method requires as inputs the SAR wet snow image and the reference SAR image of the dry snow (or the snow free terrain). After corregistration, either mutilooking or speckle filtering is applied on the two SAR intensities before constructing the backscattering ratio image. This ratio image is then georeferenced and an unique threshold of $-3 \mathrm{~dB}$ is used to discriminate the wet snow from other surfaces. The expected difference in backscattering is justified by the increased electromagnetic absorption of the wet snow. The resulting maps are successfully validated by using snow terrain optical images. Subsequently, constraints concerning both sensor and target parameters with respect to the validity of the defined threshold have been introduced [7].

In this article, we propose an alternative change detection method with X-band SAR data for wet snow detection. The goal is to introduce an algorithm which is eventually more suited to the presence of the speckle noise and is based on a slightly modified hypothesis on a wet/dry snow backscattering ratio behaviour.

The first novelty is related to the choice of the reference image. It is supposed to be the image acquired in the winter season, when the dry snow assumption is valid.

The state of the art backscattering measurements [1] indicate a complex relationship in terms of backscattering between the two types of snow, which cannot be simplified by assuming increased absorption and therefore lower backscattering of the wet snow, for all values of LIA. In order to account for this fact, we employ the multi-layer snow backscattering simulator (calibrated with the scatterometer measurements in $\mathrm{C}$ band) and analyse the wet/dry snow backscattering ratio as a function of LIA, in X band. Thereupon, we determine the range of ratio values, pointing to the presence of the wet snow. The derived range slightly differs with respect to the conventional assumption used in $\mathrm{C}$ band.

Further, the speckle noise statistics is introduced through the local estimation of the intensity ratio probability. This allows additional enhancement of the discrimination accuracy, which is illustrated through the matching of the independently obtained $\mathrm{HH}$ and VV maps. Finally, we analyse the performances 


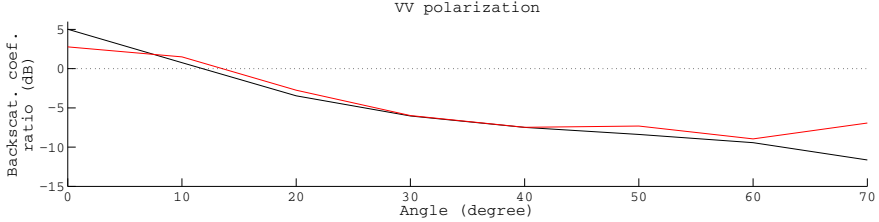

(a)

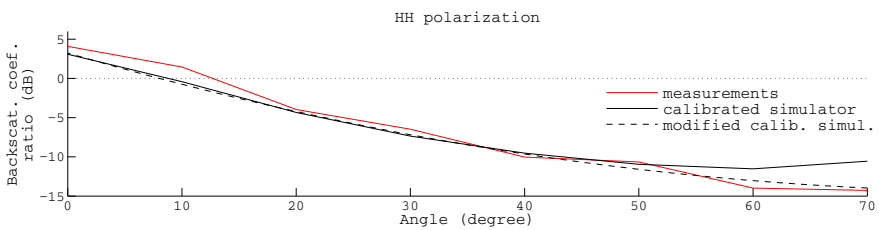

(b)

Fig. 1: Calibration of the backscattering simulator using scatterometer measurements in $\mathrm{C}$ band [1]: (a) VV, (b) $\mathrm{HH}$.

by comparing snow maps obtained using TerraSAR-X data with interpolated temperature map.

The paper is organized as follows. Section II is the core of the article, containing the description of the wet snow detection algorithm. Both the analysis of the wet/dry backscattering ratio and the stochastic approach are introduced in this section. In Section III, we present the results obtained with two TerraSAR-X dual-pol stripmap images acquired in the French Alps. This section provides the performance analyses, while Section IV concludes this article.

\section{THE DETECTION ALGORITHM}

The wet snow detection algorithm consists of five principal parts:

\section{A. Input data}

The approximate equivalence between the bare ground and the dry snow backscattering, perceived in $\mathrm{C}$ band, does not appear to be true for higher frequencies [8]. Therefore, in order to assure applicability in a wider range of frequencies, we compare directly the dry snow cover image with the mixed dry/wet snow cover one.

The following data are required as input:

- Winter SAR image, slant range geometry - image acquired during the winter season, when the dry snow assumption is fairly valid due to the air temperature at ground level;

- Melting season SAR image, slant range geometry - image acquired at the end of the winter season, when an increase in the air temperature causes melting;

- Digital Elevation Model (DEM) and Sensor \& Orbit parameters (georeferencing and derivation of LIA map);

- Approximate information about the snow cover in the region (verifying appropriateness of the proposed method);

\section{B. SAR image processing}

In this part, the input images are calibrated and corregistrated using the resampled SAR geometry intensity simulation. The slant range LIA is also derived.

\section{Wet/Dry snow backscattering ratio}

Given the fundamental role of both the snow surface and the underlying layer in snow backscattering, the local incidence angle (LIA) appears to be the most appropriate choice of an independent variable for the analysis of the wet/dry snow backscattering ratio. In order to both qualitatively and quantitatively analyse the backscattering ratio, we developed the multilayer backscattering simulator. The Integral Equation Model (IEM-B) [9] is used to simulate surface backscattering, while volume behaviour is modelled using the Quasi Crystalline Approximation with Coherent Potentials (QCA-CP) through the Dense Media Radiative Transfer (DMRT) [10].

In the region of particular interest - the French Alps, the large multilayer snow cover occurs both in the accumulation and in the melting season, containing, in the former case, inevitably present ice crust. The analysis of dry snow have shown that most of the backscattering energy comes from the continuous ice crust, rather than from the underlying ground, as it is the case with the emissivity in the passive microwave remote sensing [11]. Therefore, we assumed the dominance of this underlying backscattering component in the case of a dry snow [12]. Consequently, the layers above the ice crust are considered to be the effective snow cover. We adopt the parameters of these layers as the multi-layer (ML) simulator input data. In the case of wet snow, the surface layer is considered as the most contributory [13]. Thus, the wet snow backscattering is simulated using a single-layer (SL) approach, by adopting the parameters of the surface layer.

The derived backscattering simulator is calibrated in $\mathrm{C}$ band $(5.3 \mathrm{GHz})$ using the scatterometer measurements from [8] (Fig. 1). The applied calibration is essentially the optimization with respect to the surface parameters of both the underlying ice crust and the snow layers. After introducing in situ measured input parameters [1] (density, depth, dielectric permittivity, wetness), we derive the surface parameters of the ice crust and the ones of the snow layers, by applying the optimization algorithm based on minimizing the mean square error between the simulator output in $\mathrm{C}$ band and the measurements (LIA ranging from $0^{\circ}$ to $70^{\circ}$ ). The $\mathrm{HH}$ simulation results have been modified by extrapolating the backscattering curves after $L I A=50^{\circ}$. This is due to the observed anomaly of the IEM-B, related to the low values of dielectric permittivity, causing quite a radical increase of the surface backscattering for higher incidence angles, which is not fully consistent neither with the ground truth data, nor with the theoretical expectations.

The simulator is then applied in $\mathrm{X}$ band $(10 \mathrm{GHz})$, using the extended set of parameters, reinforced by the derived surface parameters (Table I). By slightly varying the surface roughness parameters (RMS height and correlation length) we obtain the wet/dry snow backscattering ratio (Fig. 2a), allowing us, foremost, the following qualitative interpretation: the wet snow backscattering is not necessarily inferior in $\mathrm{X}$ band, neither.

Using the derived wet/dry snow backscattering ratio, we identify the ranges of values which should indicate the wet snow presence in the ratio image (Fig. 2b). Given that the 


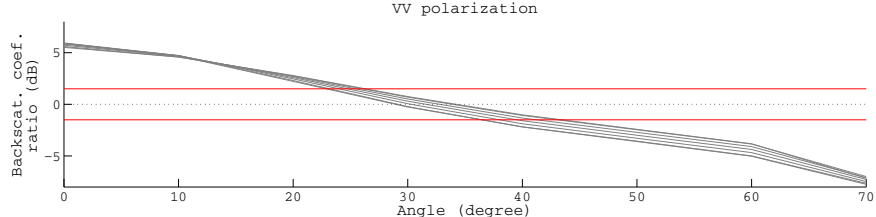

(a)(i)

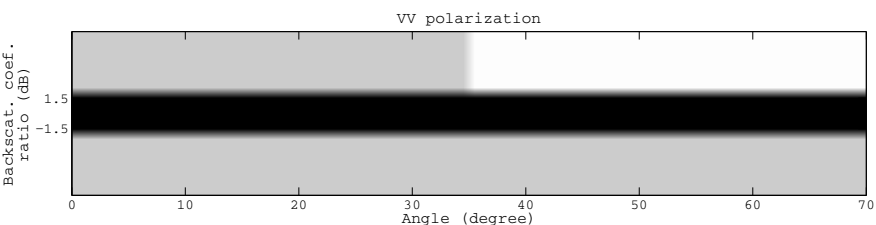

(b)(i)

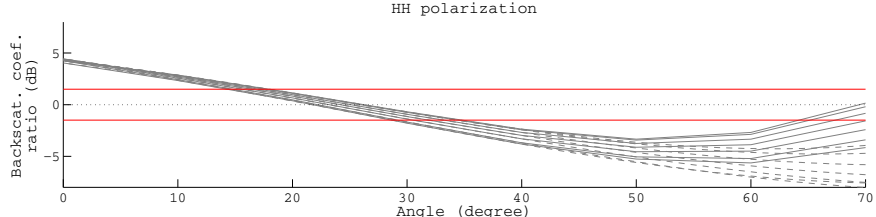

(a)(ii)

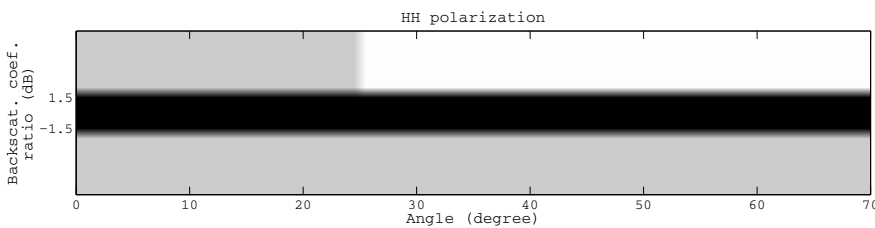

(b)(ii)

Fig. 2: Wet/dry snow backscat. ratio for input paramet. in Table I (a) and backscat. ratio values indicating wet snow (grey) and dry snow (black) (b): (i) VV, (ii) HH. Grey lines are backscat. curves for different roughness paramet. (Table I), red lines represent defined thresholds (Table II). Dashed grey lines represent simulation results, modified due to the observed IEM-B anomaly.

dry snow image is used as a reference, regions around $0 d B$ indicate dry snow presence (no change). Further, by adopting the standard hypothesis, negative regions (below $-1.5 \mathrm{~dB}$ ) are associated to the wet snow presence. However, believing that the positive backscattering difference for lower local incidence angles should also imply the wet snow, sooner than the dry one, we assign wet snow to the positive regions corresponding to the lower LIA, as well. Namely, the melting process which occurs in the upper layer gives rise to the snowpack surface backscattering, which eventually augments total snow backscattering at lower LIA.

\section{Stochastic approach}

Assuming the gaussianity of the SAR clutter, the intensity over homogeneous regions can be modelled by the Gamma probability density function (PDF), according to the fully developed speckle model [14]:

$$
\mathcal{G}(\tau \mid \nu, \mu)=\frac{1}{\Gamma(\nu)}\left(\frac{\nu}{\mu}\right)^{\nu} \tau^{\nu-1} e^{-\frac{\nu x}{\mu}},
$$

with $\mu$ being the texture intensity mean, $\nu$ - shape factor providing deviation with respect to the corresponding Gaussian distribution and $\Gamma$ - the Gamma function. If the intensity is expressed as $\frac{\mu}{\nu} X$, the random variable $X$ follows the chisquared distribution $\chi^{2}(\nu)$ with $\nu$ degrees of freedom. The

TABLE I: INPUT PARAMETERS FOR THE SNOW BACKSCATTERING SIMULATION, USED IN THRESHOLDS DERIVATION. DIFFERENT SHADES OF GREY REPRESENT DIFFERENT DRY SNOW LAYERS.

\begin{tabular}{||l|c|c|c|c||}
\hline Input parameter & \multicolumn{3}{|c||}{ Dry snow (ML) } & Wet snow (SL) \\
\hline \hline Snow density & $144 \mathrm{~kg} / \mathrm{m}^{3}$ & $185 \mathrm{~kg} / \mathrm{m}^{3}$ & $333 \mathrm{~kg} / \mathrm{m}^{3}$ & $315 \mathrm{~kg} / \mathrm{m}^{3}$ \\
\hline Wetness & $0 \%$ & $0 \%$ & $0 \%$ & $0.73 \%$ \\
\hline Snow depth & $0.24 \mathrm{~m}$ & $0.12 \mathrm{~m}$ & $0.24 \mathrm{~m}$ & $1.77 \mathrm{~m}$ \\
\hline Frequency & \multicolumn{3}{|c||}{$5.3 \mathrm{GHz}(\mathrm{C}), 10 \mathrm{GHz}(\mathrm{X})$} \\
\hline Particles effective radius & \multicolumn{3}{|c||}{$\left(0\right.$ o), $r_{\text {eff }}=225 \mu \mathrm{m}$} \\
\hline Water dielectric constant & \multicolumn{3}{|c||}{$55+j 40(\mathrm{C}), 38+j 40(\mathrm{X})$} \\
\hline Snow layers RMS height & \multicolumn{3}{|c||}{$4.5-6.5 \mathrm{~mm}$} \\
\hline Snow layers correlation length & \multicolumn{3}{|c|}{$42-82 \mathrm{~mm}$} \\
\hline Ice crust dielectric constant & \multicolumn{3}{|c|}{3.2} \\
\hline Ice crust RMS height & \multicolumn{3}{|c|}{$8.4 \mathrm{~mm}$} \\
\hline Ice crust correlation length & \multicolumn{3}{|c|}{$24 \mathrm{~mm}$} \\
\hline
\end{tabular}

ratio of two chi-squared random variables, normalized with respect to the degrees of freedom, follows the Fisher-Snedecor distribution $\mathcal{F}\left(\nu_{1}, \nu_{2}\right)$ [15]. This implies that the ratio of two Gamma random variables, having different shape factors but the same mean value is modelled using the Fisher-Snedecor distribution:

$$
\mathcal{F}\left(r \mid k, \nu_{1}, \nu_{2}\right)=\frac{\Gamma\left(\nu_{1}+\nu_{2}\right)}{\Gamma\left(\nu_{1}\right) \Gamma\left(\nu_{2}\right)} \frac{\nu_{1}}{k \nu_{2}} \frac{\left(\frac{\nu_{1} r}{k \nu_{2}}\right)^{\nu_{1}-1}}{\left(1+\frac{\nu_{1} r}{k \nu_{2}}\right)^{\nu_{1}+\nu_{2}}}
$$

The proposed stochastic approach is exactly based on the probability estimation relaying on the previously elaborated assumption. The algorithm uses the boxcar neighbourhood, coupled with the approximate maximum likelihood estimator (MLE), in order to obtain local statistics for each of the areas in the image. Due to the poor performances of the FisherSnedecor MLE, the estimation is performed rather on the normalized ratio intensity $(\xi)$ than the ratio intensity itself $(r=\mu \xi)$. If the ratio intensity $(r)$ follows the Fisher-Snedecor distribution, the normalized ratio intensity $(\xi)$ is modelled by the Beta prime distribution:

$$
\mathcal{B}^{\prime}\left(\xi \mid \nu_{1}, \nu_{2}\right)=\frac{\Gamma\left(\nu_{1}+\nu_{2}\right)}{\Gamma\left(\nu_{1}\right) \Gamma\left(\nu_{2}\right)} \frac{\xi^{\nu_{1}-1}}{(1+\xi)^{\nu_{1}+\nu_{2}}}
$$

For each local neighbourhood, we derive the mean value $(\mu)$, normalize the texture locally and estimate $\nu_{1}$ and $\nu_{2}$ parameters. This way, we define the probability density function $\left(\mathcal{B}_{(i, j)}^{\prime}\right)$ for every region in the image. By integrating the obtained PDF with respect to the normalized texture, we get the cumulative distribution function $\left(B_{(i, j)}^{\prime}\right)$ for the normalized threshold of the central pixel:

$$
\begin{aligned}
i_{\text {out }}(i, j) & =B_{(i, j)}^{\prime}\left(\frac{T_{2}(i, j)}{\mu(i, j)}\right)-B_{(i, j)}^{\prime}\left(\frac{T_{1}(i, j)}{\mu(i, j)}\right)= \\
& =\int_{\frac{T_{1}(i, j)}{\mu(i, j)}}^{\frac{T_{2}(i, j)}{\mu(i, j)}} \mathcal{B}_{(i, j)}^{\prime}(\xi) d \xi .
\end{aligned}
$$

This value is the probability of the ratio fitting the predefined range of values or exactly the wet snow probability. The thresholds $\left\{T_{1}(d B), T_{2}(d B)\right\} \in\{-1.5,1.5,-\infty, \infty\}$, can be deduced from Fig. $2 b$, as functions of the LIA. 


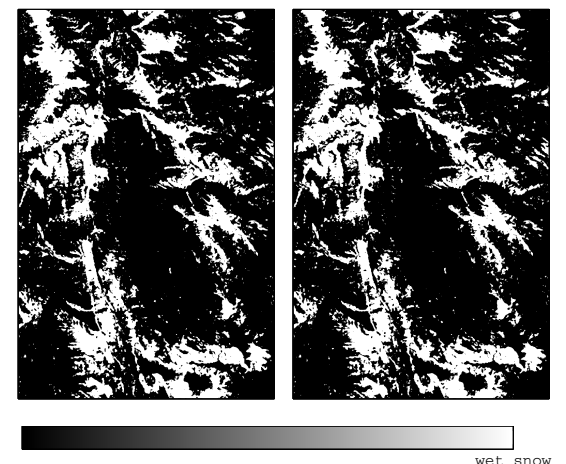

(a)

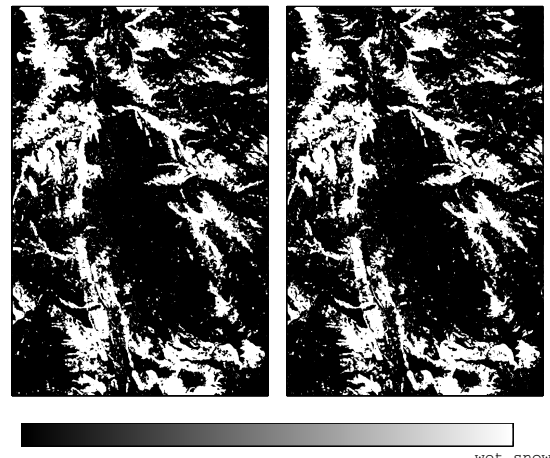

(b)

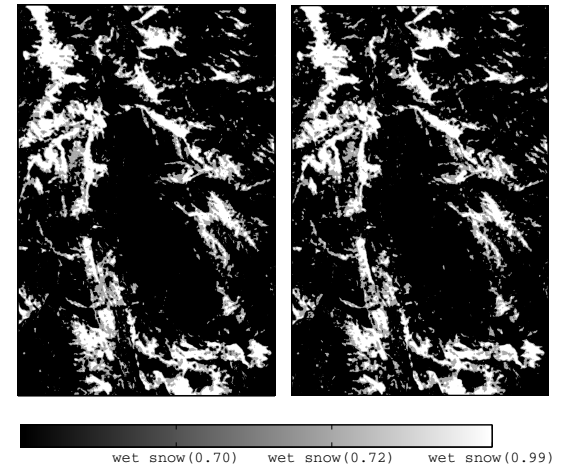

(c)

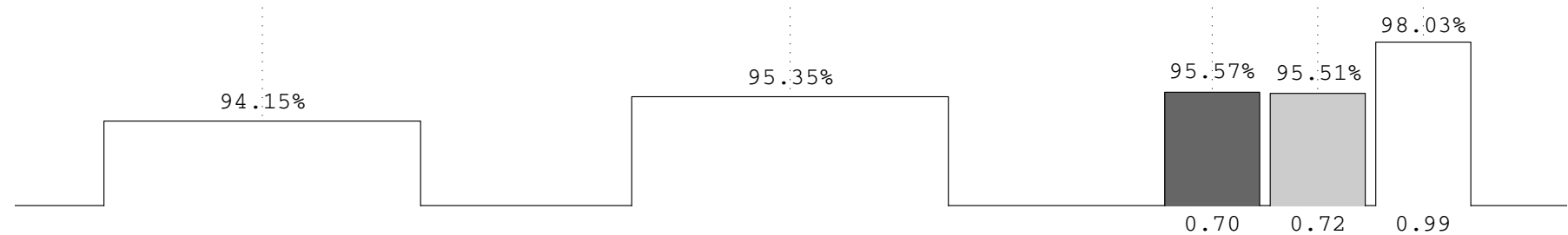

(d)

Fig. 3: The comparison between $\mathrm{HH}$ (left) and VV (right) polarization maps obtained after: (a) filtering the thresholded ratio of input images, (b) thresholding the ratio of speckle filtered input images, (c) thresholding the probability map with $70 \%, 72 \%$ and $99 \%$ confidence level. (d) HH-VV matching.

\section{E. Confidence level}

The obtained wet snow probability map is transformed into the wet snow binary map by applying the confidence level. It reflects the level of certainty that the derived map indeed represents wet snow regions.

\section{PERFORMANCE ANALYSES}

The proposed algorithm is illustrated by the results obtained using two X-band TerraSAR-X stripmap images acquired over the Grandes Rousses massif near Grenoble, France: the winter image, acquired on the 8th of February, 2009, holding for the dry snow assumption (according to the local meteorological data and the DEM - $88 \%$ of the area is at the altitude $>1500 \mathrm{~m}$ ); and the melting season image, acquired on the 2nd of March, 2009, in the presence of wet snow, according to the same source. The local incidence angle map is computed using the DEM (Datum: WGS-84, UL Geo: $\left.5^{\circ} 57^{\prime} 3.64^{\prime \prime} E, 45^{\circ} 24^{\prime} 15.21^{\prime \prime} N\right)$.

For comparison, we provide in Fig. 3 three pairs of binary maps ( $\mathrm{HH}$ and $\mathrm{VV}$ ) derived using different change detection methods. Firstly, we present the results obtained by using the criteria from Fig. $2 b$ on the filtered ratio of original input images (Fig. 3a). Further, the same criteria is applied on the ratio of formerly speckle filtered input images (Fig. 3b). Finally, we include the proposed stochastic approach, and present the results obtained with the proposed method, using a very high confidence level - 99\% (Fig. 3c).

The quantitative correspondence between the independently obtained $\mathrm{HH}$ and VV maps (Fig. 3) significantly augments in the case of the proposed stochastic approach. By applying an unconstrained optimization technique, we estimate that the maps in Fig. 3a and Fig. 3b approximately correspond to the probability maps thresholded with $70 \%$ and $72 \%$ confidence level, respectively. Increase of confidence level decreases the fraction of wet snow, but augments the certainty.

The verification of the obtained results is performed using the local temperature measurements at the ground level. The measurements data, provided by the Électricité de France $(E D F)$, are related to the area of interest (Grandes Rousses massif) at the same date (3rd of March, 2009), meaning that comparison with the available SAR images was possible. The single point measurements are acquired at 36 stations in the wider region ( 7 in the area of interest), and spatialized using the kriging interpolation method.

The procedure is based on the stated fact that wet snow presence is characteristic for the local ground temperature above $0^{\circ} \mathrm{C}$, while dry snow can be found below $0^{\circ} \mathrm{C}$. The temperature measurements are compared to the obtained wet snow probability map (Fig. 4). Quantitative evaluation of the comparison is done by calculating a spatial correlation, using a large sliding boxcar (Fig. 4c). This way, by calculating the correlation coefficient for each subregion, we get a more precise insight into the matching. The approximate overlapping between the high temperature regions and the high probability regions (two independent information), is pointing to the validity of the obtained results. Although this assessment, due to the heavily interpolated temperature and consequently quite a large boxcar used for calculating the correlation, cannot help us demonstrate all the subtleties of the proposed method, it remains an important indication of its validity.

In order to demonstrate that the estimated wet snow regions (Fig. 4a) are not confounded with a bare ground, we superpose to the wet snow binary map $(99 \%)$ the mask derived from the DEM - Altitude $>1500 \mathrm{~m}$. This altitude is the least favourable assumption (highest value) of the snow line, for the area and 


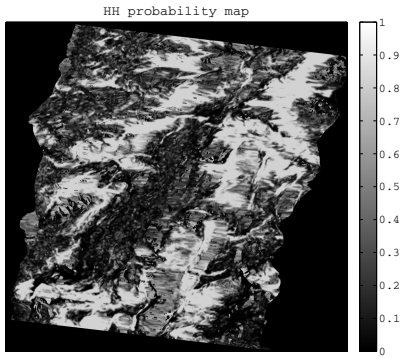

(a)

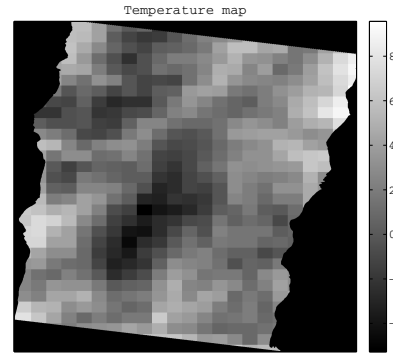

(b)

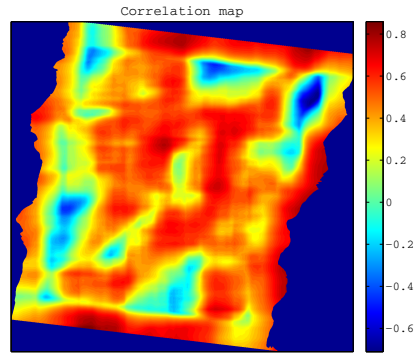

(c)

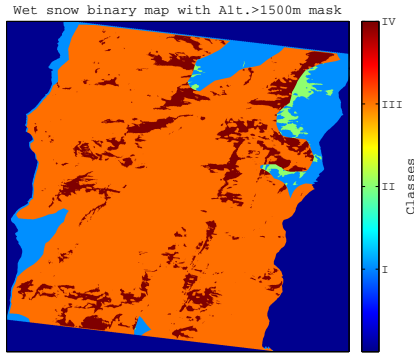

(d)

Fig. 4: Georeferenced maps: (a) HH wet snow probability map; (b) interpolated ground level temperature map, (c) Correlation between the HH wet snow probability map and the ground level temperature map, (d) HH wet snow binary map (99\%) superposed to the mask Altitude > $1500 \mathrm{~m}$ : Classes I (no wet snow) and II (wet snow) - below $1500 \mathrm{~m}$, Classes III (no wet snow) and IV (wet snow) - above $1500 \mathrm{~m}$.

the date of interest (Fig. 4d). Only $10.7 \%$ of the detected wet snow pixels risks to be misestimated.

\section{CONCLUSIONS}

Snow backscattering simulations, reinforced by the state of the art measurements, resulted in the conclusion that the difference in backscattering of wet and dry snow occurs to be significantly dependent on the local incidence angle and on the operating frequency. Consequently, we have proposed an alternative version of the conventionally used wet snow detection method, by analysing a wet/dry snow backscattering ratio in $\mathrm{X}$ band and moderately modifying the range of values in the ratio image pointing to the presence of wet snow. Also, we chose preferably the winter image as the reference, avoiding constraints related to the frequency dependent relation between dry snow and bare ground backscattering and therefore allowing application in wider frequency range. Finally, instead of directly thresholding the ratio of multitemporal images, by considering the spatial correlation, we rather estimated the probability of the wet snow occurrence, making the algorithm stochastic.

The plausibly modified assumption of the wet/dry snow backscattering ratio, the implicitly introduced spatial correlation between the wet snow areas, and the possibility to vary the level of confidence of the wet snow binary maps by thresholding the obtained probability map, are altogether the supplements brought by the introduced stochastic approach to the ensemble of change detection techniques in snow mapping.

Further refinements of the proposed detection method will assume the three main directions. First of all, in order to make it more solid, we intend investing efforts in improving the validation procedure. In the second direction, the quantitative interpretation of the wet/dry snow backscattering ratio will be improved, which should allow more accurate discrimination between different regions in Figure 2b, in terms of LIA. Concerning the third direction, further work will mostly consist in adjusting the proposed method to polarimetric SAR input data [16]. The idea is to exploit the dual-pol images in the probability derivation.

\section{ACKNOWLEDGEMENT}

The authors would like to thank to the $E D F$ and the MétéoFrance for providing us the ground truth temperature data and other input parameters of interest, and to the Institut national de l'information géographique et forestière (IGN France) for the DEM. We owe particular gratitude to anonymous reviewers whose comments and suggestions improved significantly the presented work.

\section{REFERENCES}

[1] T. Strozzi and C. Matzler, "Backscattering measurements of alpine snowcovers at 5.3 and $35 \mathrm{ghz}$," IEEE Trans. Geosci. Remote Sens., vol. 36, no. 3, pp. 838-848, 1998.

[2] F. T. Ulaby, W. H. Stiles, and M. AbdelRazik, "Snowcover influence on backscattering from terrain," IEEE Trans. Geosci. Remote Sens., vol. GE-22, no. 2, pp. $126-133$, march 1984.

[3] J. Shi, J. Dozier, and H. Rott, "Snow mapping in alpine regions with synthetic aperture radar," IEEE Trans. Geosci. Remote Sens., vol. 32, no. 1 , pp. $152-158,1994$.

[4] H. Rott, "Thematic studies in alpine areas by means of polarimetric sar and optical imagery," Advances in Space Research, vol. 14, no. 3, pp. 217-226, 1994.

[5] H. Rott and T. Nagler, "Capabilities of ers-1 sar for snow and glacier monitoring in alpine areas," in Proceedings of ERS-1 2nd symposium, 1994, pp. 965-970.

[6] T. Nagler and H. Rott, "Retrieval of wet snow by means of multitemporal sar data," IEEE Trans. Geosci. Remote Sens., vol. 38, no. 2, pp. 754-765, 2000.

[7] R. Magagi and M. Bernier, "Optimal conditions for wet snow detection using radarsat sar data," Remote Sensing of Environment, vol. 84, no. 2, pp. $221-233,2003$.

[8] T. Strozzi, "Backscattering measurements of snowcovers at 5.3 and 35 ghz," Ph.D. dissertation, University of Bern, Bern, CH, 1996.

[9] A. K. Fung, D. Schutzer, and K. S. Chen, Microwave Scattering and Emission Models for Users. Norwood, MA, USA: Artech House, 2010.

[10] L. Tsang, J. Kong, and K. Ding, Scattering of Electromagnetic Waves, Vol. 1:Theory and Applications. Wiley Interscience, 2000.

[11] C. Matzler and A. Wiesmann, "Extension of the microwave emission model of layered snowpacks to coarse-grained snow," Remote Sensing of Environment, vol. 70, no. 3, pp. 317 - 325, 1999.

[12] N. Besic, G. Vasile, J. Chanussot, S. Stankovic, J.-P. Dedieu, G. d'Urso, D. Boldo, and J.-P. Ovarlez, "Dry snow backscattering sensitivity on density change for swe estimation," in Proc. IGARSS, Munich, Germany, 2012, pp. 4418-4421.

[13] N. Besic, G. Vasile, J. Chanussot, S. Stankovic, D. Boldo, and G. d'Urso, "Wet snow backscattering sensitivity on density change for swe estimation," in Proc. IGARSS, Melbourne, Australia, 2013.

[14] J. W. Goodman, "Some fundamental properties of speckle," J. Opt. Soc. Amer, vol. 53, no. 11, pp. 1145-1149, 1976.

[15] L. Bombrun, G. Vasile, M. Gay, and F. Totir, "Hierarchical segmentation of polarimetric SAR images using heterogeneous clutter models," IEEE Trans. Geosci. Remote Sens., vol. 49, no. 2, pp. 726-737, 2011.

[16] A. Lessard-Fontaine, S. Allain-Bailhache, J.-P. Dedieu, and Y. Durand, "Multi-temporal dry and wet snow mapping in alpine context using polarimetric radarsat-2 time-series," in Proc. IGARSS, Munich, Germany, 2012, pp. 1569-1571. 